\title{
Improvements in Pyrolysis of Wastes in an Externally Heated Rotary Kiln (Experimental Study on Heat Transfer Enhancement) ${ }^{*}$
}

\author{
Tomoko SUZUKI $^{* *}$, Teruyuki OKAZAKI ${ }^{* *}$, Kenji YAMAMOTO**, \\ Hiroyuki NAKATA $^{* * *}$ and Osamu FUJITA ${ }^{* * * *}$ \\ ${ }^{* *}$ Hitachi, Ltd, \\ 832-2 Horiguchi, Hitachinaka, Ibaraki, Japan \\ E-mail: tomoko.suzuki.tk@hitachi.com \\ ***Hitachi-GE Nuclear Energy, Ltd., \\ 3-1-1 Saiwai-cho, Hitachi, Ibaraki, Japan \\ ****Hokkaido University, \\ N13 W8 Kita-ku, Sapporo, Hokkaido, Japan
}

\begin{abstract}
The effects of rotating speed and internal structure on the performance of an externally heated rotary kiln for waste pyrolysis were investigated. A newly developed method was adopted to evaluate the overall heat transfer coefficient $k_{m-w}$ from the inner wall to the wastes for this purpose. The experimental results revealed that $k_{m \text {-w }}$ monotonically increased with the number of lifters and their height. When six lifters $200 \mathrm{~mm}$ in height were attached to the inner wall of the kiln, the mean value of $k_{m-w}$ increased from $38.6 \mathrm{~W} / \mathrm{m}^{2} \mathrm{~K}$ to $45.3 \mathrm{~W} / \mathrm{m}^{2} \mathrm{~K}$ at $2.7 \mathrm{rpm}$. In addition, $k_{m-w}$ increased to $50.1 \mathrm{~W} / \mathrm{m}^{2} \mathrm{~K}$ when the rotating speed was increased to $4.0 \mathrm{rpm}$. In the water vaporization phase during the course of the pyrolysis process, the height of the lifters had a significant influence on $k_{m-w}$. However, the number of lifters had a significant impact on $k_{m-w}$ in the pyrolysis phase of the plastic-based wastes. According to measurements, a $10 \%$ increase in $k_{m-w}$ could be obtained when installing lifters to attain a ratio of lifter height $H_{l}$ to the thickness of the waste layer $H_{w}$ larger than 0.45 or when arc length between two lifters $L_{l}$ to the arc length of the interface between the wastes and the kiln wall $L_{w}$ was larger than 1.
\end{abstract}

Key words: Recycling, Gasification, Heat Transfer Enhancement, Pyrolysis, Rotary Kiln

\section{Introduction}

Externally heated rotary kilns are often used for gasification systems to melt generated municipal wastes because they are easy to operate, subsidiary materials for gasification such as coke, limestone, and oxygen are unnecessary, and pyrolysis gas and char with high calorific value are produced. However, it is necessary to improve heat transfer when the required heat value increases due to the changed quantities and properties of wastes because wastes are externally heated through the kiln wall.

The overall heat transfer coefficient $k_{m-w}$ from a kiln to the wastes is a fundamental characteristic value for evaluating heat transfer in the kiln. We established a method of measuring overall heat transfer coefficient $k_{m-w}$ through an experiment using a batch-type kiln in a previous study ${ }^{(1)}$. On the other hand, numerous studies have been made on the

${ }^{*}$ Received 28 Aug., 2008 (No. T2-07-1064) Japanese Original : Trans. Jpn. Soc. Mech. Eng., Vol.74, No.743, B (2008),

pp.1586-1592 (Recieved 21 Nov., 2007) [DOI: 10.1299/jtst.3.532] 
rotating speed and internal structure of rotary kilns since these parameters are generally known to influence the mixing behavior and residence time of the material that pass through a kiln ${ }^{(2)-(6)}$. However, few studies have been done on enhancing heat transfer from the kiln wall to the material layer, although radial heat conduction in there has been investigated $^{(7)-(9)}$.

In this study, we clarify the influence that the internal structure and rotating speed have on overall heat transfer coefficient $k_{m-w}$ from the kiln wall to the wastes and on the required time for pyrolysis, in order to obtain design principles that enhance the heat transfer.

\section{Nomenclature}

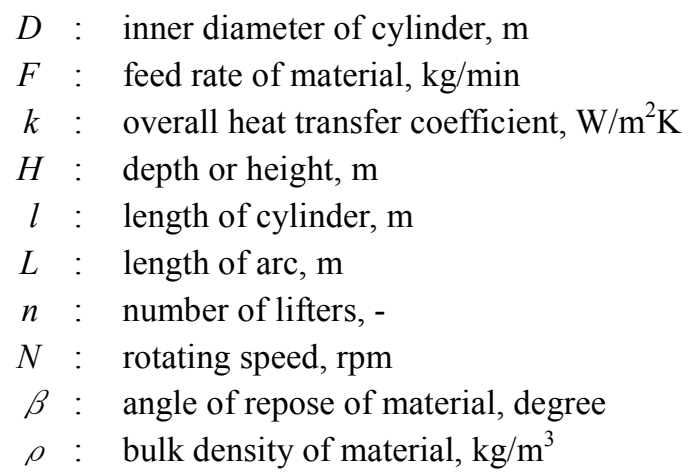

\section{Subscripts}

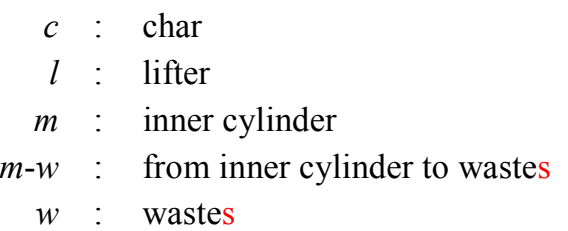

\section{Experimental Method}

\subsection{Experimental Apparatus and Structure of Pyrolysis Reactor}

The experimental apparatus and the structure of the pyrolysis reactor have been described previously ${ }^{(1)}$.

\subsection{Measurement Method for Overall Heat Transfer Coefficient}

There is no established method for direct measurement of the overall heat transfer coefficient $k_{m-w}$. In this study, we measured it using the previously reported method ${ }^{(1)}$. The heat balance of the experimental system was evaluated in all experiments to check the reliability of the measured values.

\subsection{Experimental Conditions}

The lifters shown in Fig. 1 were installed in the inner cylinder to improve mixing of wastes. Experimental conditions are listed in Table 1. Case No. 1 was the basic condition, and No.2 was the case where the inner wall temperature of

\begin{tabular}{|c|c|c|c|c|}
\hline \multirow{2}{*}{$\begin{array}{l}\text { Case } \\
\text { No. }\end{array}$} & \multirow{2}{*}{$\begin{array}{l}\text { Kiln wall } \\
\text { temperature } \\
\left({ }^{\circ} \mathrm{C}\right)\end{array}$} & \multirow{2}{*}{$\begin{array}{c}\text { Rotating } \\
\text { speed } \\
(\mathrm{rpm})\end{array}$} & \multicolumn{2}{|c|}{ Lifter } \\
\hline & & & $\begin{array}{c}\text { Number } \\
(-)\end{array}$ & $\begin{array}{l}\text { Height } \\
(\mathrm{mm})\end{array}$ \\
\hline 1 & 555 & 2.7 & 0 & - \\
\hline 2 & 630 & 2.7 & 0 & - \\
\hline 3 & 555 & 2.7 & 6 & 50 \\
\hline 4 & 555 & 2.7 & 6 & 100 \\
\hline 5 & 555 & 2.7 & 6 & 200 \\
\hline 6 & 555 & 2.7 & 3 & 100 \\
\hline 7 & 555 & 4 & 0 & - \\
\hline 8 & 555 & 4 & 6 & 200 \\
\hline
\end{tabular}


the kiln was $630{ }^{\circ} \mathrm{C}$. In cases 3 to 6 , the height of the lifters was changed from 50 to 200 $\mathrm{mm}$, and their number was either 3 or 6 . Cases 7 and 8 had a kiln rotating speed of $4.0 \mathrm{rpm}$.

\subsection{Method of Fixing Lifters}

In the experiments where lifters were installed, boards $25 \mathrm{~mm}$ thick and 1,500 $\mathrm{mm}$ long were fixed radially on the inner wall of the kiln. Figure 1 is a photograph of the inner cylinder of a kiln. Six lifters $100 \mathrm{~mm}$ in height were spot-welded to the inner wall surface so as to prevent them from being heated by heat conduction.

\subsection{Composition of Simulated Wastes}

We used the same raw materials as in our previous paper ${ }^{(1)}$. By using simulated wastes we could objectively compare the results between experiments. The dry-basis composition is listed in Table 2. Before all experiments, water was added to get $10 \%$ moisture content for the wastes. This value was based on the mean value measured between the dryer exit and the pyrolytic kiln inlet in an actual plant.

\section{Experimental Results and Discussion}

\subsection{Influence on Pyrolysis Characteristics}

The relationships between the elapsed time after feeding and the volume of pyrolysis gas are plotted in Figs. 2 (a)-(d). Three peaks appear in all cases. The first is the peak for the evaporation of moisture, the second is that for the pyrolysis of grain, paper, and wood, and the third is that for the pyrolysis of plastics as reported before ${ }^{(1)}$. We considered that pyrolysis had ended when the production of pyrolysis gas was finished. The results for the basic conditions without lifters, i.e. case No. 1 and case No. 2, are shown in Fig. 2 (a). The time required for pyrolysis was $42 \mathrm{~min}$ in case No. 1, but only $30 \mathrm{~min}$ in case No. 2 . This meant pyrolysis was promoted by the increased heating temperature. The effect of lifter height on the behavior of pyrolysis is shown in Fig. 2 (b). Six lifters were installed in these cases. Increasing the height of the lifters from 50 to $200 \mathrm{~mm}$ reduced the time for pyrolysis from 40 to $33 \mathrm{~min}$. In particular, the first and the second peaks appeared within a short time, and the evaporation of moisture and the pyrolysis of grain and paper were thought to be enhanced. The effects of the number of lifters for the $100 \mathrm{~mm}$ lifter height are plotted in Fig. 2 (c). The pyrolysis time was shortened from 42 to $37 \mathrm{~min}$ by installing three lifters and was shortened to 35 min with six lifters. The first peak was not be influenced by the number of lifters while the second and third peaks appeared within a short time by increasing the number of lifters. The effect of rotating speed is shown in Fig. 2 (d). Increasing rotating speed from 2.7 to $4.3 \mathrm{rpm}$ reduced the time for pyrolysis from 42 to $38 \mathrm{~min}$. Furthermore, in case No. 8 with six $200 \mathrm{~mm}$ lifters installed in the kiln and rotating speed increased to 4.0 $\mathrm{rpm}$, the pyrolysis time was shortened to $31 \mathrm{~min}$, which was almost the same as for case No. 2 where the inner wall temperature was the higher temperature, $630{ }^{\circ} \mathrm{C}$. 


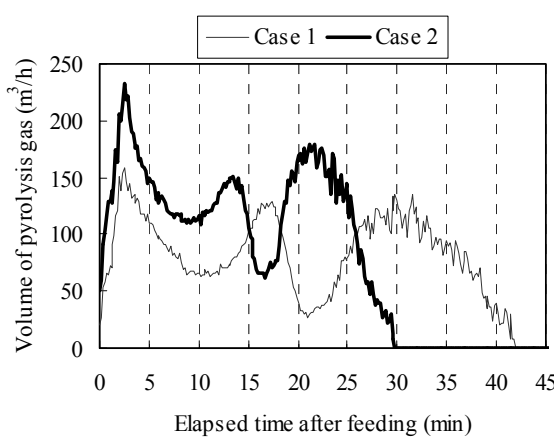

Fig. 2 (a) Effect of reactor temperature on pyrolysis behavior

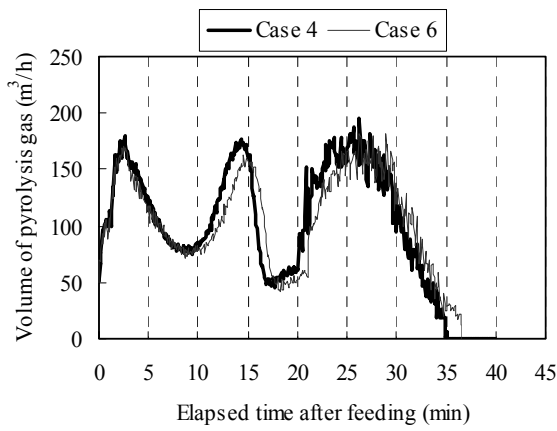

Fig. 2 (c) Effect of number of lifters on pyrolysis behavior

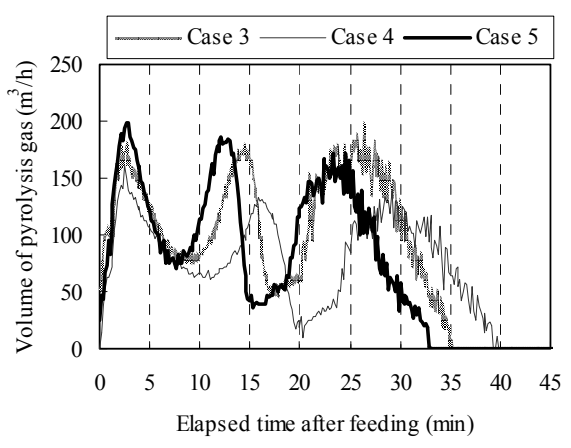

Fig. 2 (b) Effect of height of lifters on pyrolysis behavior

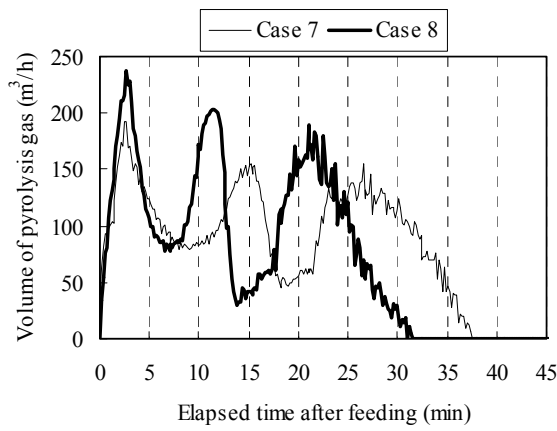

Fig. 2 (d) Effect of rotating speed on pyrolysis behavior

One reason why pyrolysis is promoted with the increase in rotating speed of the drum may be that solids are mixed more thoroughly in the transverse direction. The rotating speed and the material filling ratio of the drum in a commercial kiln are selected to make the material layer flow transversely in what is called "rolling" or "cascading" ${ }^{(10)}$. In the rolling state, solids continuously flow on the edge of the waste layer, while the core remains in the layer's center. The heating speed in the core is slower than that on the edge because heat is only transferred by conduction ${ }^{(7)}$. By contrast, radiation and convection are the main paths of heat transfer in the cascading state because the whole layer is flowing constantly due to the high rotating speed. We considered that pyrolysis was accelerated due to the mixing of the core materials by the lifters attached to the drum as much as when the rotating speed was increased. It is known that the transfer rate of the material that pass through a kiln increases and the residence time decreases with increasing rotating speed in a continuous-type kiln ${ }^{(4,5)}$. Therefore, there is the possibility that, when the rotating speed is increased too much, the wastes pass through the drum before they are pyrolyzed entirely. On the other hand, it has also been reported that the residence time of the material in a kiln with lifters is much longer than that in a kiln without lifters ${ }^{(5)}$. From the above, we can see that the combination of lifters and increased rotating speed effectively improves pyrolysis.

\subsection{Influence on Overall Heat Transfer Coefficient}

The relationship between the height of the lifters and $k_{m-w}$ is plotted for the cases with six lifters in Fig. 3 (a). These are the average $k_{m \text {-w }}$ values during pyrolysis of the model wastes. The overall heat transfer coefficient $k_{m-w}$ increased linearly with the height of the lifters. With $200 \mathrm{~mm}$ lifters, $k_{m-w}$ was $45.3 \mathrm{~W} / \mathrm{m}^{2} \mathrm{~K}$ while the value for the no-lifter case was $38.6 \mathrm{~W} / \mathrm{m}^{2} \mathrm{~K}$. The relationship between the number of lifters and $k_{m-w}$ is plotted for the case of $100 \mathrm{~mm}$ lifters in Fig. 3 (b). $k_{m-w}$ also increased with the number of lifters. The 
relationship between the rotating speed of the kiln and $k_{m-w}$ is plotted in Fig. 3 (c). $k_{m-w}$ increased from $38.6 \mathrm{~W} / \mathrm{m}^{2} \mathrm{~K}$ to $43.4 \mathrm{~W} / \mathrm{m}^{2} \mathrm{~K}$ by increasing the rotating speed from 2.7 $\mathrm{rpm}$ to $4.0 \mathrm{rpm}$. At $4.0 \mathrm{rpm}, k_{m-w}$ increased to $50.1 \mathrm{~W} / \mathrm{m}^{2} \mathrm{~K}$ by installing six $200 \mathrm{~mm}$ lifters.

Pyrolysis of waste proceeds through three successive phases ${ }^{(1)}$. First, moisture evaporates (phase 1), then celluloses such as grain, paper, and wood are pyrolyzed (phase 2), and finally plastics are pyrolyzed (phase 3). According to these reactions, three peaks appear in the pyrolysis gas volume. On the other hand, $k_{m-w}$ is not constant during the pyrolysis, but it increases with wastes temperature. This suggests the possibility that the effect of lifters may be different in each phase. To confirm this, the process of pyrolysis was divided into three phases based on pyrolysis gas production, and the average value of $k_{m-w}$ was calculated in each phase. In this experiment, a suitable height and number of lifters were selected to improve $k_{m-w} 10 \%$ or more from the basic case. The effect of lifter height on the overall heat transfer coefficient is plotted in Fig. 4 (a). The vertical axis shows the ratio of $k_{m-w}$ in the improved cases to that in case 1 (the basic case). In phase 1 , the $50 \mathrm{~mm}$ lifters had a slight effect, while the ratio of $k_{m-w}$ increased by $18 \%$ for the $200 \mathrm{~mm}$ lifters. However, in phase 3 , this was improved by more than $10 \%$ even with $50 \mathrm{~mm}$ lifters. The effect of the number of lifters on the overall heat transfer coefficients is plotted in Fig. 4 (b) for the case with $100 \mathrm{~mm}$ lifters. In phase $1, k_{m-w}$ was scarcely improved regardless of the number of lifters, while it was improved $6 \%$ with three lifters and $17 \%$ with six lifters in

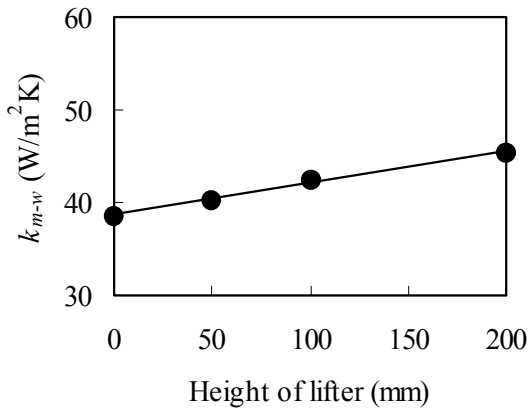

Fig. 3 (a) Relationship between height of lifters and overall heat transfer coefficient

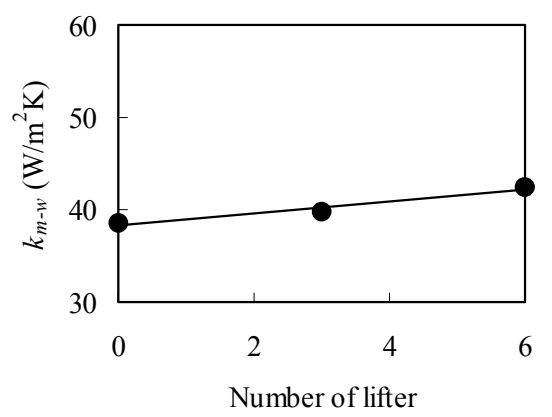

Fig. 3 (b) Relationship between number of lifters and overall heat transfer coefficient

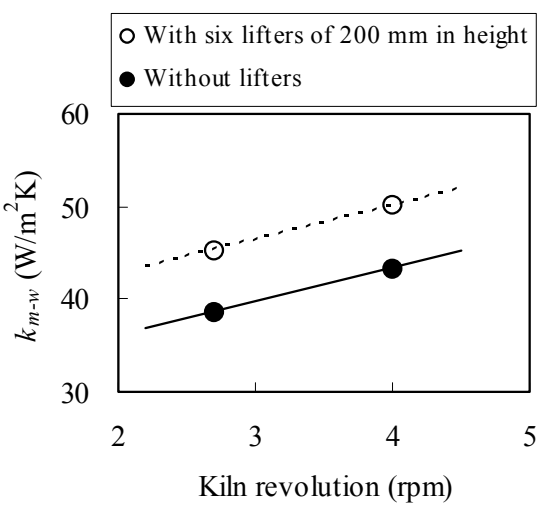

Fig. 3 (c) Relationship between rotating speed and overall heat transfer coefficient phase 3. We evaluated the geometric relationship between the waste layer and the lifters to clarify why the effect of lifters was different in the three phases. The geometric relationship between the waste layer and lifters is outlined in Fig. 5. The height of the waste layer $H_{w}$ was about $430 \mathrm{~mm}$ and the arc length was $1420 \mathrm{~mm}$ just after feeding according to the experiment conducted at ambient temperature. We considered that the configuration of the layer in phase 1 was similar to this. On the other hand, the height of the char layer $H_{c}$ was about $110 \mathrm{~mm}$ and the arc length after pyrolysis $L_{c}$ was $680 \mathrm{~mm}$, according to the measurement after the pyrolysis process. This configuration was considered to be similar to that in phase 3 . 


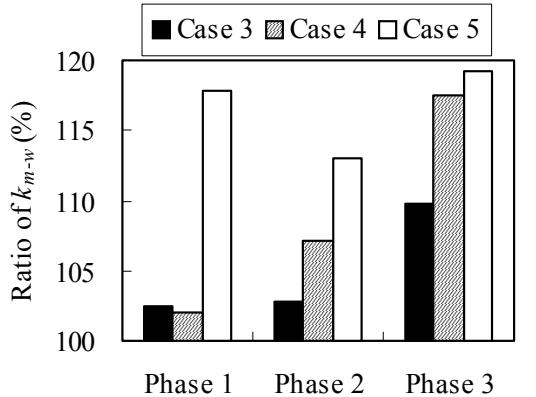

Fig. 4 (a) Effect of lifter heights on overall heat transfer coefficient

The ratios of lifter height $H_{l}$ to the depth of waste layer $H_{w}$ and to the depth of char layer $H_{c}$ are listed in Table 3. Using the $50 \mathrm{~mm}$ lifters, the ratio of lifter height to the waste height $H_{l} / H_{w}$ was 0.12 , and the ratio of lifter height to the char height $H_{l} / H_{c}$ was 0.45. As shown in Fig. 4(a), only the $200 \mathrm{~mm}$ lifters showed a marked heat transfer enhancement in phase 1 , while $10 \%$ improvement of $k_{m-w}$ was observed even with $50 \mathrm{~mm}$ lifters in phase 3 . These results suggested that the heat transfer enhancement due to installation of lifters appeared only when the $H_{l} / H_{w}$ or $H_{l} / H_{c}$ exceeded a certain value. Under the conditions, the criterion was about 0.45 . The ratios of arc length between two lifters $L_{l}$ to the arc length of wastes in contact with the inner surface of kiln $L_{w}$ and to that of the char layer $L_{c}$ are listed in Table 4. As shown in Fig. 4(b), in phase 1, the number of lifters scarcely affected $k_{m-w}$. This was because the height of the lifters, $100 \mathrm{~mm}$, was not enough as mentioned above. However, in phase 3, there was a $17 \%$ enhancement of $k_{m-w}$ in the case with six lifters, while there was a $6 \%$ enhancement with three lifters. The ratio $L_{l} / L_{c}$ in six lifter case is less than 1 . Therefore, in order to enhance heat transfer efficiently by installing lifters, it is desirable to set the number of lifters so that the ratio $L_{l} / L_{w}$ or $L_{l} / L_{c}$ is less than 1 .

Table 3 Height ratios of lifters to the wastes

\begin{tabular}{|l|c|c|}
\multicolumn{1}{c}{ (char) } \\
\hline$H_{l}(\mathrm{~mm})$ & $H_{l} / H_{w}$ & $H_{l} / H_{c}$ \\
\hline 50 & 0.12 & 0.45 \\
\hline 100 & 0.23 & 0.91 \\
\hline 200 & 0.47 & 1.82 \\
\hline
\end{tabular}

\subsection{Design of Continuous Type Kiln}

We applied the above results to design a continuous-type kiln. The kiln specifications are listed in Table 5. It is advantageous to design the kiln so that the ratio $H_{l} / H_{w}\left(H_{l} / H_{c}\right)$ exceeds 0.45 and that the ratio $L_{l} / L_{w}\left(L_{l} / L_{c}\right)$ is less than 1 to maximize the effect of lifters to increase $k_{m-w}$. However, it is impossible to predict the layer thickness of the wastes moving
Table 4 Ratio of spacing between lifters to arc length of interface between wastes (char) and kiln wall

\begin{tabular}{|c|c|c|c|}
\hline Number of lifters & $L_{l}(\mathrm{~m})$ & $L_{l} / L_{w}$ & $L_{l} / L_{c}$ \\
\hline 0 & 3.14 & 7.31 & 4.62 \\
\hline 3 & 1.05 & 2.43 & 1.54 \\
\hline 6 & 0.52 & 1.22 & 0.77 \\
\hline
\end{tabular}


in the kiln and the arc length of the contact surface with the kiln wall. Therefore, it is necessary to estimate these values first. Equation (1) for the layer thickness of powder $H_{f}$ passing through a horizontal rotary kiln ${ }^{(12)}$ was used to estimate the layer thickness and arc length.

$$
F=0.74\left(\frac{H_{f}}{D}\right)^{2.05} \frac{D^{4} \cdot N \cdot \cot \beta \cdot \rho}{l}
$$

The concept of estimation is outlined in Fig. 6. First, a small section $\mathrm{L}_{1}$ is divided from the outlet port of the kiln in the axial direction, and the layer height $H_{f}$ is calculated by using Eq. (1). The distribution of the waste layer height in the rotating kiln is estimated by repeating this calculation for the inlet port. The arc length of the contact surface between the waste layer and the kiln wall is estimated with the layer thickness. The values of $H_{w}$ and $L_{w}$ estimated under the conditions shown in Table 5 are plotted in Fig. 7 as a function of the distance from the inlet port of the kiln. $H_{w}$ was calculated to be about $1.0 \mathrm{~m}$ and $L_{w}$ was calculated to be about $3.1 \mathrm{~m}$ at the inlet port. Using these results, we calculated the number of lifters $n$ which satisfied the condition $L_{l} / L_{w}=1 . n$ was estimated to be 2 at the inlet port, as shown in Fig. 8. Three lifters were required $15 \mathrm{~m}$ from the inlet port because $n$ was limited to an integer value. Four lifters were required in the region from $15 \mathrm{~m}$ to $18 \mathrm{~m}$ from the inlet port, five from $18 \mathrm{~m}$ to $19 \mathrm{~m}$, and six to the end of the drum. $H_{l}$ can be determined to satisfy the condition $H_{l} / H_{w}>0.45$ by using the height of wastes shown in Fig. 7. A commercial continuous-type kiln designed using these results should achieve optimal performance.

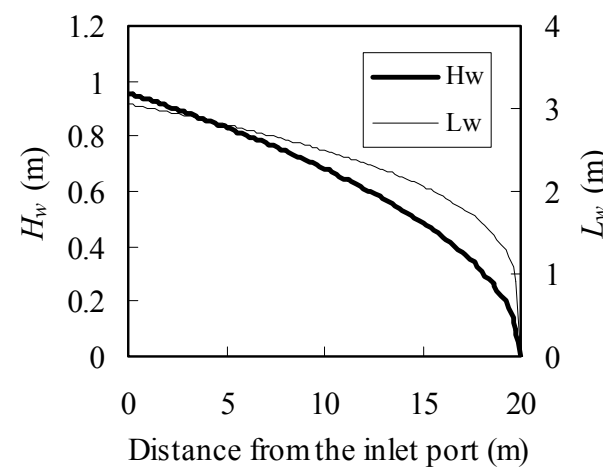

Fig. 7 Relationship between distance from inlet port and estimated value of $H_{w}$ and $L_{w}$
Table 5 Design specifications

\begin{tabular}{|l|c|}
\hline \multicolumn{1}{|c|}{ Item } & Specification \\
\hline Kiln inner diameter & $2 \mathrm{~m}$ \\
\hline Kiln length & $20 \mathrm{~m}$ \\
\hline Kiln revolution & $3 \mathrm{rpm}$ \\
\hline Waste feed speed & $70 \mathrm{~kg} / \mathrm{min}$ \\
\hline Waste bulk density & $150 \mathrm{~kg} / \mathrm{m}^{3}$ \\
\hline Waste angle of repose & $40^{\circ}$ \\
\hline
\end{tabular}

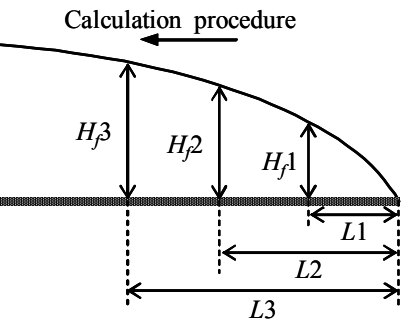

Fig. 6 Conceptualization to determine layer height 


\section{Conclusions}

We examined the influence the internal structure and rotating speed of an externally heated rotary kiln on pyrolysis time and overall heat transfer coefficient $k_{m-w}$ from the kiln to the wastes, and drew the following conclusions.

(1) When six lifters $200 \mathrm{~mm}$ in height were installed in the kiln and the rotating speed was $4.0 \mathrm{rpm}$, the pyrolysis time was shortened and was the same time as obtained when the pyrolysis temperature was increased from $555^{\circ} \mathrm{C}$ to $630^{\circ} \mathrm{C}$.

(2) The overall heat transfer coefficient $k_{m-w}$ increased with the number of lifters and their height. The number of lifters had a significant effect on $k_{m-w}$.

(3) The overall heat transfer coefficient $k_{m-w}$ was improved more than $10 \%$ by designing the lifters so that the ratio of their height $H_{l}$ to the layer height of the waste $H_{w}$ exceeded 0.45 . In addition $k_{m-w}$ was also improved by more than $10 \%$ when the ratio of the arc length between two lifters $L_{l}$ to the arc length of the contact surface of the kiln and the waste layer $L_{w}$ was less than 1 .

\section{References}

(1) Suzuki, T., Okazaki, T., Yamamoto, K., Nakata, H., and Fujita, O., Transactions of the Japan Society of Mechanical Engineers, Vol.74, No.743, B(2008), pp.1579-1585.

(2) Sherritt, R. G., Caple, R., Behie, L. A., and Mehrotra, A. K., Canadian Journal of Chemical Engineering, Vol. 71, No. 3 (1993), pp. 337-346.

(3) Sherritt, R. G., Caple, R., Behie, L. A., and Mehrotra, A. K., Canadian Journal of Chemical Engineering, Vol. 72, No. 2 (1994), pp. 240-248.

(4) Hatzilyberis, K. S. and Androutsopoulos, G. P., Drying Technology, Vol. 17, No. 4-5 (1999), pp. 759-774.

(5) Li, S. Q., Yan, J. H., Li, R. D., Chi, Y., and Cen, K. F., Powder Technology, Vol. 126, No. 3 (2002), pp. 217-227.

(6) Lui, X., Specht, E., and Mellmann, J., ZKG International, Vol. 58, No. 2 (2005), pp. 62-73.

(7) Dhanjal, S. K., Barr, P. V., and Watkinson, A. P., Metallugical and Materials Transactions B, Vol. 35, No. 6 (2004), pp. 1059-1070.

(8) Ferron, J. R. and Singh, D. K., American Institute of Chemical Engineers Journal, Vol.37, No.5 (1991), pp. 747-758.

(9) Boateng, A. A. and Barr, P. V., International Journal of Heat and Mass Transfer, Vol.39, No. 10 (1996), pp. 2131-2147.

(10) Henein, H., Brimacombe, J. K., and Watkinson, A. P., Metallurgical Transactions B, Vol. 14, No. 2 (1983), pp. 191-205.

(11) Henein, H., Brimacombe, J. K., and Watkinson, A. P., Metallurgical Transactions B, Vol. 14, No. 2 (1983), pp. 207-220.

(12) The Association of Powder Process Industry and Engineering, Kilns for Processes, (1985), p. 66, Nikkan Kogyou Shinbun, Ltd. (in Japanese). 